\title{
Liposuction devices: technology update
}

This article was published in the following Dove Press journal:

Medical Devices: Evidence and Research

21 July 2014

Number of times this article has been viewed

\author{
Sachin M Shridharani' \\ Justin M Broyles ${ }^{2}$ \\ Alan Matarasso' \\ 'The Department of Plastic Surgery, \\ Manhattan Eye, Ear and Throat \\ Hospital, New York, NY, USA; ${ }^{2}$ The \\ Department of Plastic Surgery, The \\ Johns Hopkins University School of \\ Medicine, Baltimore, MD, USA
}

\begin{abstract}
Since its introduction by Illouz and others over 30 years ago, suction-assisted lipectomy/liposuction/lipoplasty has evolved tremendously and has developed into one of the most popular procedures in aesthetic plastic surgery. Liposuction is an effective procedure employed to treat localized adipose deposits in patients not suffering from generalized obesity. These accumulations of subcutaneous fat often occur in predictable distributions in both men and women. A cannula connected to a suction-generating source allows for small incisions to be strategically placed and large volumes of fat to be removed. This fat removal leads to improved harmonious balance of a patient's physique and improved body contour. Various surgical techniques are available and have evolved as technology has improved. Current technology for liposuction includes suction-assisted lipectomy, ultrasound-assisted, power-assisted, laser-assisted, and radiofrequency-assisted. The choice of technology and technique often depends on patient characteristics and surgeon preference. The objective of this review is to provide a thorough assessment of current technologies available to plastic surgeons performing liposuction.
\end{abstract}

Keywords: laser, lipoplasty, mesotherapy, power-assisted, radiofrequency, ultrasound, water-assisted, coolsculpting

\section{Introduction}

Liposuction is routinely employed by plastic surgeons concerned with removing subcutaneous adipose deposits in various areas in the body to improve figure flaws and create a more balanced physique. It is one of the most commonly performed surgical procedures in aesthetic plastic surgery. ${ }^{1-4}$ In 2012, suction lipectomy was the second most frequently performed cosmetic surgical procedure, with 313,011 patients undergoing lipoplasty. In the past 15 years, liposuction has seen a 77\% increase in its number of surgeries performed. Furthermore, suction lipectomy is the most common aesthetic surgical procedure performed in men. ${ }^{5}$ Indeed, liposuction consistently ranks among the most common aesthetic surgery procedures.

Subsequent to Illouz's presentation of a technique for removing subcutaneous fat with a blunt cannula attached to a suction generating device at the 1982 Annual Meeting of the American Society of Plastic and Reconstructive Surgeons, the procedure has undergone many refinements and evolved with improvement in techniques and technology. ${ }^{6-10}$ A variety of technological advancements have been added to the traditional method of suctioning fat: ultrasound, power, laser, and radiofrequency (RF) are the primary adjuncts. Each technology has its own unique set of benefits and complications. ${ }^{11}$
Correspondence: Sachin M Shridharani Manhattan Eye, Ear and Throat Hospital, Department of Plastic Surgery, 210 East 64th Street, New York, NY, USA

Tel +l 2127027502

Fax + I 2127027787

Emailsachin_shridharani@hotmail.com 
All of the technologies effectively contour excessive fatty deposits. The ultimate goals/holy grail of new technologies is often to remove excess adipose tissue while providing concomitant skin tightening. The benefits of a technique that contracts skin, without lengthy incisions for skin excision cannot be understated. ${ }^{12}$ The ideal liposuction device would be capable of optimizing several processes, simultaneously. First, the device removes excess fat without compromising the viability of the overlying skin envelope. Second, the soft tissue envelope contracts around the area of aspirated adipose tissue. Third, the device is safe and applicable for use on patients under local tumescent anesthesia. Fourth, the device results in minimal bruising and swelling, leading to a shorter postoperative recovery period. ${ }^{11}$ To date, no device has consistently proven and shown increased efficacy in achieving greater skin contraction versus a different device. In addition, when a clinician evaluates a patient and is able to palpate a "roll" of soft tissue in the anatomic area of concern, one must appreciate that this palpable "roll" is both skin and fat. Liposuction removes the fat, but not the excess skin. Hence, the ideal system would achieve both goals. Although the indications for performing liposuction have historically been rooted in treating naturally occurring fatty deposits during the aging process, various pathologic conditions warrant employing the procedure: lymphedema; issues with leakage around colostomy and urostomy sites caused by bulging, fatty skin folds; "insulin tumors" caused by the injection of insulin into the subcutaneous fat; multiple familial angiolipomatosis; gynecomastia; benign symmetrical lipomatosis; retroviral medication-induced lipodystrophy; and steroid-induced Cushing's disease are a few examples.

It is the aim of the authors to provide a thorough review of the history of liposuction technology, current devices employed, emerging medical equipment, and future directions. ${ }^{13}$

\section{Historical perspective}

The first known attempt at removal of subcutaneous fat through a small incision was performed by French surgeon Charles Dujarrier in 1921, who employed a sharp uterine curette and operated on the calves of a Folies Bèrgere dancer. The procedure was successful in fat removal; however, it eventually resulted in the amputation of a leg due to injury to the femoral artery. ${ }^{14}$

Decades passed before new reports to contour fat were published. In 1972, there were further official reports and/or presentations of utilizing medical instruments primarily for removal of subcutaneous fat. German surgeon,
Joseph Schrudde, reported on his 8-year experience with the technique of "lipexheresis" at the International Society of Aesthetic Plastic Surgery meeting in Brazil. This technique called for using a sharp uterine curette introduced through a small access incision. The surgical instrument was used in a "windshield wiper" type motion in the subcutaneous layer. This technique is in contrast to what subsequently evolved as discrete "Swiss-cheese" tunneling to remove the fat. Three years later, Schrudde provided a more detailed report on the procedure in Lagenbeck's Archives of Surgery. ${ }^{15-19}$

Around this same time period, an American surgeon, Bahman Teimourian, also used a sharp uterine curette to remove subcutaneous adipose tissue. His contribution is less attributed to technological advancement as actual technique. As opposed to the "windshield wiper" method, Teimourian appreciated the significance of creating separate tunnels in the adipose layer. These changes in technique led to technological innovation, with the advent of slender cannulas designed to create tunnels, rather than scrape out fat. Though he initially reported the procedure in a secondary thigh lift, he later expanded the technique to many other areas of the body. ${ }^{20-25}$

\section{Current devices}

\section{Traditional suction-assisted lipectomy}

During the late 1970s and early 1980s, a number of surgeons were concurrently contributing to the technique and technology that later became traditional liposuction. Until that time, surgeons were using sharp curettes, which led to several unwanted complications, including excess bleeding, contour irregularities, lack of overlying skin contraction, seroma formation, and even frank skin necrosis. In 1977, brothers Arpad and George Fisher were the first surgeons to describe adding suction to assist the process of fat extraction. ${ }^{26}$ The Fisher brothers utilized a sharp instrument connected to a suction device, which led to increased efficiency of fat removal; however, the complication rate remained high. Therefore, the technique was not widely adopted.

Similar to Teimourian, the contributions of Ulrich Kesselring were rooted more in technical refinements, which clearly led to the appreciation for the need for better technology. Kesselring used sharp instruments attached to a suction-generating device; however, he introduced the instruments in the deep fat layer immediately superficial to muscle fascia. Furthermore, his selection of young, healthy women with minimal to no loss of skin elasticity contributed 
significantly to improved surgical outcomes, helping renew interest in liposuction benefits. ${ }^{27-30}$

As previously mentioned, Yves-Gerard Illouz (Paris, France) is often credited with the major technological advances to liposuction instruments. A known collaborator/ colleague of Kesselring, Illouz's modification of the sharp curette to a blunt-tip cannula was spawned from the observation of a high complication rate due to collateral tissue laceration and damage. The blunt cannula was increasingly easy to navigate through tissue and remove fat while still maintaining the integrity of adjacent soft tissue structures. ${ }^{31}$ Not only did adopting the blunt cannula technology lead to an overall decrease in complication rate, but further allowed a standardized safer technique for surgeons with varying levels of experience to adopt. Small access incisions were made in the skin, and the blunt cannula was introduced through these incisions to aspirate fat in the deep subcutaneous layer. Cannulas with different curves, lengths, and diameters were manufactured. The cannulas had two basic design features consisting of a blunt end with a round tip and a lateral opening that one was to always direct away from the skin surface in order to avoid the creation of irregular skin contour. There was a notched area on the cannula to help the surgeon orient positioning of the opening. A $10 \mathrm{~mm}$ cannula was used for large fatty deposits, and an $8 \mathrm{~mm}$ cannula was used for the knees, ankles, abdomen, and arms. Finally, a $5 \mathrm{~mm}$ cannula was used for the face. The cannula was connected to a suction pump by a semirigid transparent tube, which allowed for the isolated fat to be visualized as it was suctioned. The endpoint of liposuction occurred when aspirated fat changed in color from a pure yellow to bloody appearance. It was at this point, the cannula was to be inserted in a different tunnel as described by Kesselring. ${ }^{29}$ This technique continued to become refined, and the potential of liposuction as a staple of aesthetic plastic surgery was validated. Two additional French surgeons, Fournier and Otteni, introduced the utilization of syringes in place of the suction machine as the source of negative pressure connected to a non-cutting edge cannulae. ${ }^{32}$ Over the years, the cannula length changed, and inner diameters were made smaller. It is therefore rare to use a cannula greater than $5 \mathrm{~mm}$ (diameter) on the body and $2.4 \mathrm{~mm}$ (diameter) on the face. In addition, cannula design has changed to have several openings to optimize fat extraction.

\section{Ultrasound-assisted liposuction}

Ultrasound-assisted liposuction (UAL) is a form of liposculpting, which employs ultrasonic energy to allow for a more selective tissue lipolysis. Zocchi ${ }^{10}$ initially described the technique, where he utilized a two-stage process of selective tissue lipolysis using an ultrasonic probe followed by traditional suction-assisted lipectomy (SAL) to evacuate the fat. The selective adipose lipolysis seen in UAL can be attributed to the transformation of electrical into mechanical energy via an ultrasonic probe that vibrates at frequencies in excess of 16 $\mathrm{kHz}$. This oscillating sound wave produces a negative pressure vector that overcomes molecular forces selectively within adipose tissue leading to cavitation and cellular fragmentation. ${ }^{33}$ The large-scale cellular disruption is later aspirated in a second stage liposuction. Rohrich et $\mathrm{al}^{34}$ confirmed that UAL generates significantly higher levels of several intracellular adipocyte enzymes than SAL, confirming the notion that adipocytes are mechanically lysed in larger amounts. One of the reported benefits of UAL over other forms of energy- and thermalassisted suction-assisted lipoplasty is caviation formation of the air bubbled in the tumescent fluid. This process results in a "crow bar" effect of streaming intact fat cells and adipocytederived stem cells so that these can then be used for successful fat grafting.

Supporters of UAL claim that adipocyte cavitation prior to SAL decreases blood loss and operative time while providing for less ecchymosis and discomfort as well as improved contouring in areas with an abundance of fibrous tissue, such as the back and chest. ${ }^{35,36}$ While the evidence to substantiate claims of decreased operative time and ecchymosis are mixed, several studies have confirmed that UAL is effective in cases of secondary liposuction as well as liposuction in fibrotic areas such as the male flank or chest area. ${ }^{37,38}$ Beckenstein and Grotting demonstrated that UAL was effective in $70 \%$ of secondary liposculpting cases. ${ }^{37}$ Additionally, Fodor and Watson ${ }^{38}$ directly compared UAL with SAL and supported UAL's superiority in sculpting fibrotic areas when compared with SAL. Finally, contemporary, third-generation UAL devices such as VASER ${ }^{\mathrm{TM}}$ (Solta Medical, Hayward, CA, USA) (Figure 1), allow for greater fragmentation of adipocytes at a lower energy setting, using pulsed rather than continuous energy. ${ }^{9}$

Critics of UAL claim that the technology is expensive, requires larger incisions, and carries the risk of thermal burns. ${ }^{39,40}$ While UAL remains promoted by some authors, the reported use and market share appears to be in decline, ${ }^{41}$ likely due to a combination of the aforementioned factors and the advent of newer technologies with safer side-effect profiles and decreased learning curves. ${ }^{39}$

\section{Power-assisted liposuction}

Further advances in technology led to a device that allowed less overall decrease in operator fatigue. The emergence of 


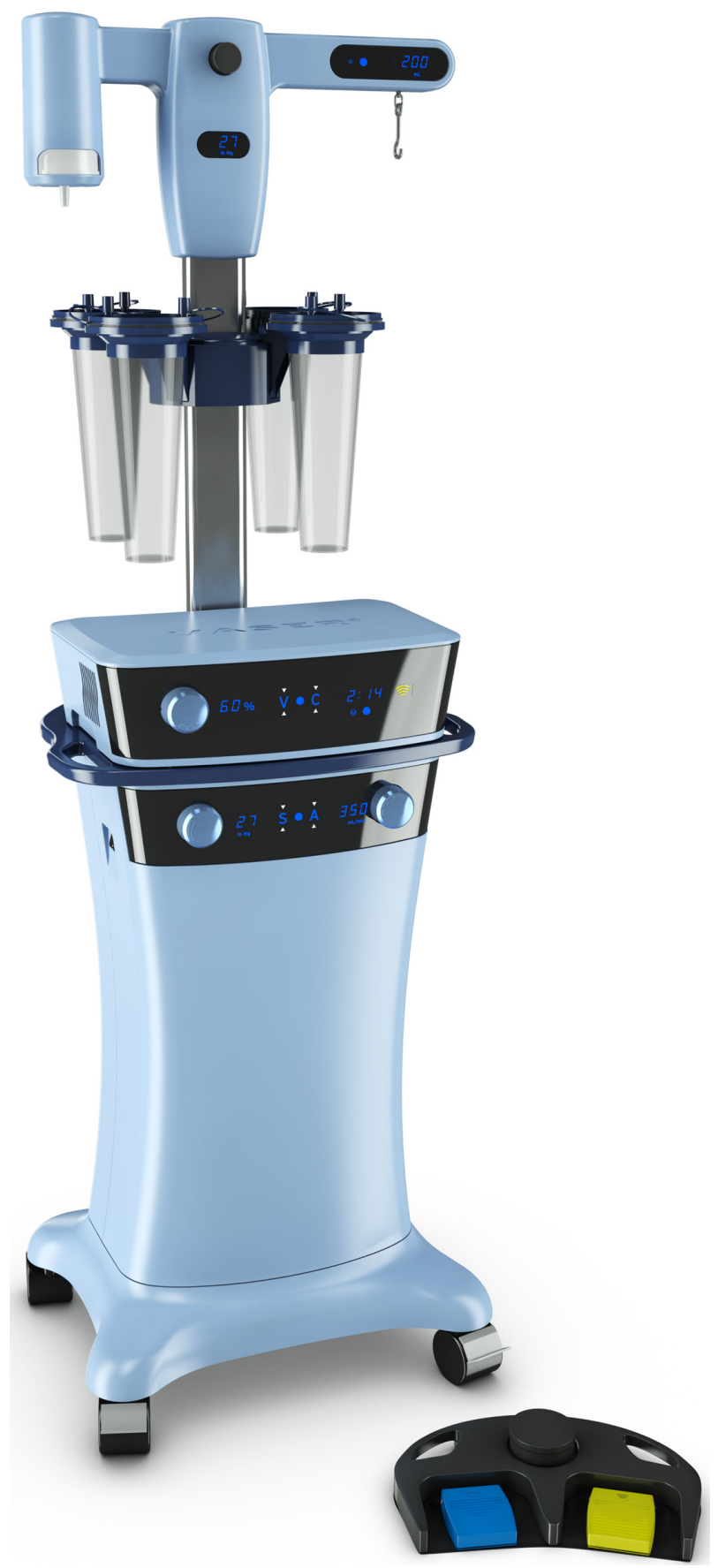

Figure I VASER TM Lipo machine.

Note: VASER ${ }^{\text {TM}}$, Solta Medical, Hayward, CA, USA.

PAL, a rapidly vibrating cannula, quickly became a mainstay in the armamentarium of plastic surgeons. ${ }^{8}$ The first such device (1998) receiving US Food and Drug Administration (FDA) approval was from MicroAire Surgical Instruments (Charlottesville, VA, USA) (Figure 2). The indication was "for removal of tissue or fluid ... including suction lipoplasty for the purpose of aesthetic body contouring." The firstgeneration device was powered by medical-grade nitrogen $\left(\mathrm{N}_{2}\right)$ or by compressed air tanks attached to the MicroAire

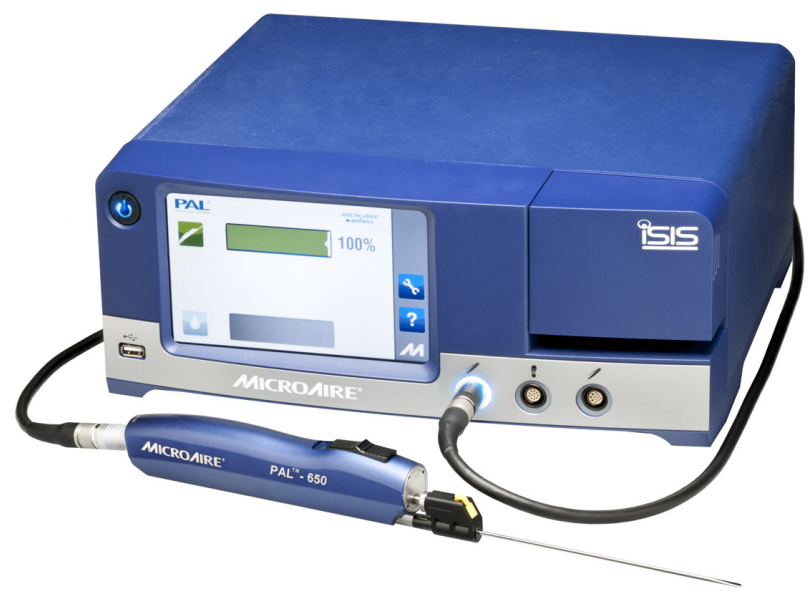

Figure 2 Power-assisted liposuction.

Note: MicroAire Surgical Instruments ${ }^{\mathrm{TM}}$, Charlottesville, VA, USA.

handle and suction tubing. The vibrating cannula reciprocated at 2,000-4,000 cpm with a $2 \mathrm{~mm}$ stroke. The speed of cannula movement could be adjusted according to the surgeon's preference. Subsequent generations became powered by a quieter electric source instead of medical-grade compressed air. ${ }^{42}$

Advocates of power-assisted liposuction (PAL) find the cannula breaks up fibrous fat much more readily than does traditional SAL. Furthermore, there is less plugging/ congestion of the cannula due to constant motion and vibration of the suction cannula. Many surgeons have noted the process of PAL to be less labor-intensive than traditional SAL. Furthermore, operative times can be decreased..$^{43}$ One author (SMS) noted in the Journal of American Medical Association improved ease of using PAL in fibrotic fat seen in HIV (human immunodeficiency virus) retroviral medicationinduced cervical lipodystrophy/buffalo hump. ${ }^{44}$

The disadvantages of PAL technology routinely expressed are additional cost, learning curve, vibration transmitted to the surgeon's upper extremity, and noise associated with the device. ${ }^{42}$

\section{Laser-assisted liposuction}

Laser-assisted liposuction (LAL) was first described in 1994 by Apfelberg et al. ${ }^{7}$ This group from California performed a preliminary investigation that used a neodymium-doped, yttrium aluminum garnet (Nd-YAG) laser within the liposuction cannula. Although initial trials sought to demonstrate superiority over conventional SAL, the FDA did not approve the technique. ${ }^{7,45}$ Since this initial study, several investigators have sought to utilize laser energy of different wavelengths to induce adipocyte lysis in an effort to decrease intraoperative blood loss and postoperative ecchymosis while improving cutaneous tightening. 
Several laser companies are utilizing laser technology as an adjunct to liposuction. The largest market share in the United States for LAL belongs to SmartLipo ${ }^{\mathrm{TM}}$ (Cynosure Inc., Westford, MA, USA) (Figure 3). Another company with a laser platform that has expanded the technology to liposuction is Sciton (Palo Alto, CA, USA) with its ProLipo PLUS ${ }^{\text {TM }}$ product (Figure 4). In its current fashion, LAL is performed either simultaneously while performing SAL or in a two-stage procedure using LAL prior to performing SAL.

LAL utilizes the principles of selective photothermolysis to preferentially lyse adipocytes while leaving surrounding structures unaffected. ${ }^{46}$ Different laser wavelengths may vary in their relative effectiveness in targeting substances present in the subcutaneous environment, including collagen, fat, vascular structures, hemoglobin, and water. Thus, lasers achieve

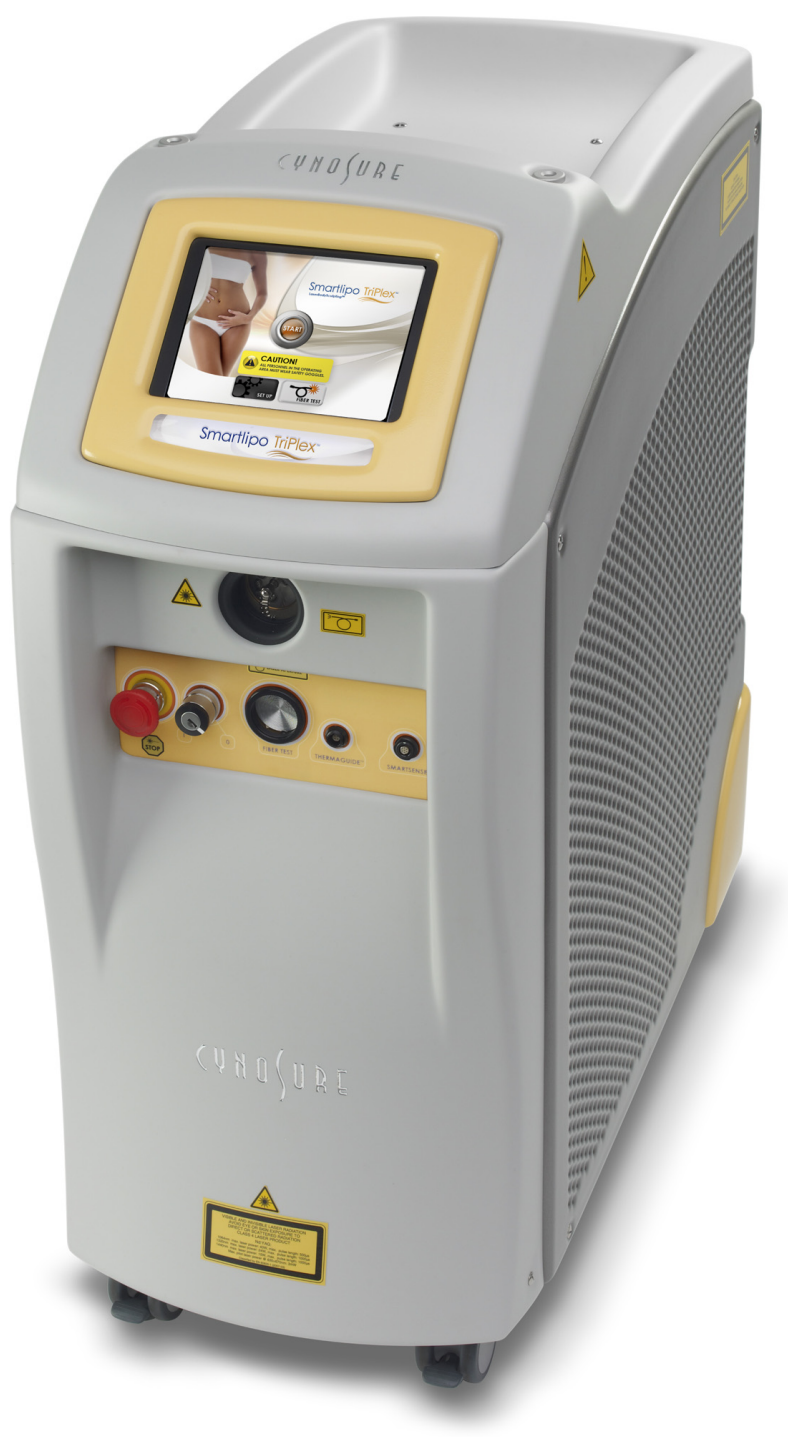

Figure 3 SmartLipo ${ }^{\mathrm{TM}}$.

Note: Cynosure Inc., Westford, MD, USA.

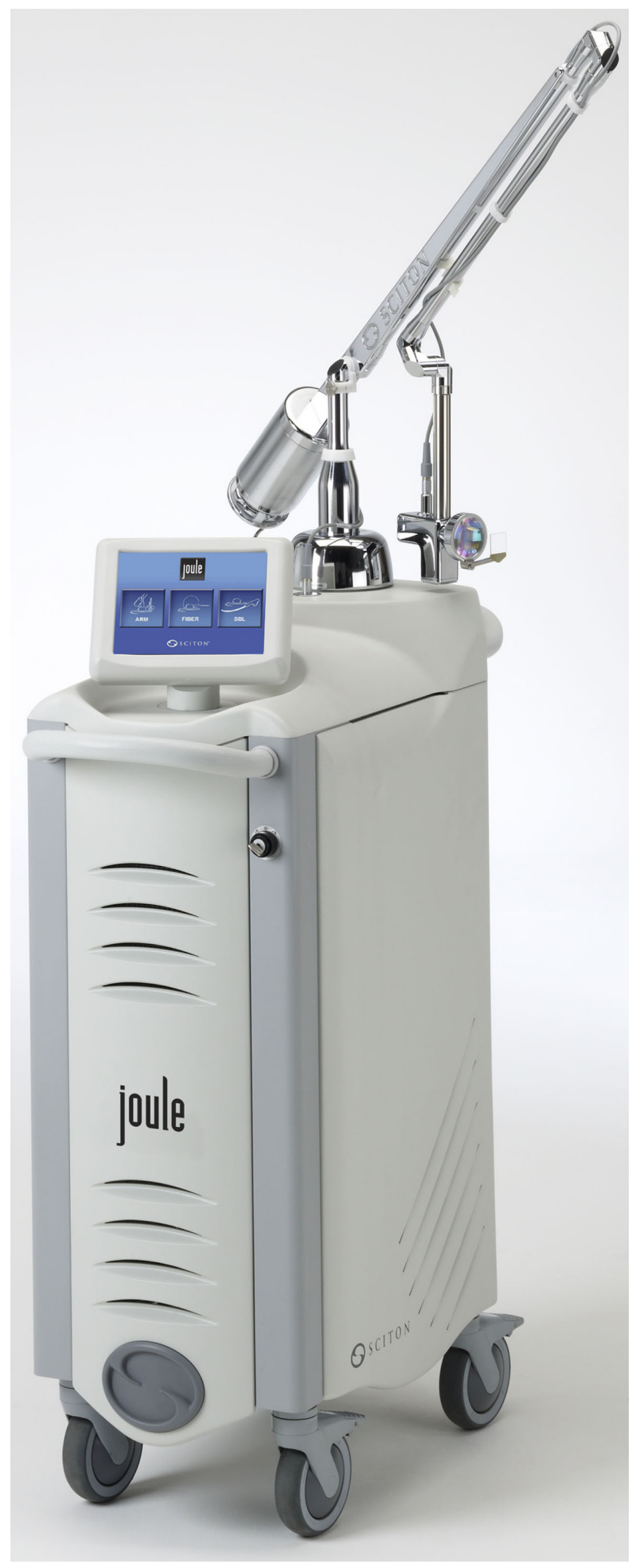

Figure 4 ProLipo PLUS ${ }^{\mathrm{TM}}$.

Note: Sciton, Palo Alto, CA, USA.

their desired effect in LAL via photolysis of adipose cells, photocoagulation of small vessels, liberation of adipocyte lipases, and contraction of dermal collagen. ${ }^{47-49}$

The most commonly utilized lasers in cosmetic dermatology are the Nd:YAG 1,064 nm, 1,320 nm, 2,010 nm, $980 \mathrm{~nm}$ 
diode laser, $924 \mathrm{~nm}$, and the $975 \mathrm{~nm}$; however, the three major lasers evaluated for LAL are the 1,064 nm Nd:YAG, the $980 \mathrm{~nm}$ diode, and the 1,064/1,320 nm Nd:YAG lasers. ${ }^{50}$ The 1,064 nm Nd:YAG is the most studied and has the greatest evidence for safety and tolerability. The $980 \mathrm{~nm}$ diode laser utilizes high power settings that provide for greater utility in dense areas containing large fat deposits, such as the thigh and abdomen. The 1,064/1,320 nm Nd:YAG demonstrates a greater selectivity for dermal collagen, with the added potential to induce skin tightening and neocollagenesis. Additionally, the $1,320 \mathrm{~nm}$ laser converts hemoglobin to methemoglobin, which may enhance hemostasis, making this laser ideal for highly vascular areas. ${ }^{50}$ The $1,440 \mathrm{~nm}$ pulsed laser has 60 times greater selective absorption of water when compared with the $1,064 \mathrm{~nm}$ laser, therefore leading to more efficient fat coagulation. ${ }^{51}$ Increased wavelength for larger surface areas with LAL has also shown in randomized, blinded studies to result in up to $17 \%$ skin contraction and $25 \%$ improvement in skin elasticity. ${ }^{51}$ Furthermore, a superficial version of LAL, using a side-light firing laser (Cellulaze; Cynosure, Westford, MA, USA) has shown significant reduction in cellulite long-term, with $25 \%$ thicker dermis on B-mode ultrasound and $29 \%$ improvement in skin elasticity. ${ }^{51,52}$

The disadvantages of LAL include the potential of thermal injury, high costs of equipment, and prolonged procedural time. Initial studies evaluating first-generation laser devices showed, in randomized trials, no increased cosmetic benefits of LAL when compared with traditional SAL. ${ }^{7}$ The emerging laser technology utilizes varying wavelengths with different effects of the surrounding environment, leading to promising dermal physiologic changes with decreased complications. $^{53}$

\section{Water-assisted liposuction}

The concept behind Water-assisted liposuction (WAL) utilizes a thin, targeted, fan-shaped jet, called Body-Jet ${ }^{\mathrm{TM}}$ (Human Med, Schwerin, Germany), to inject fluid during liposuction which loosens fat cells while minimizing surrounding soft tissue collateral damage. A piston pump powers the system and forces pressurized fluid through a closed tubing system. Subsequently, the infiltration fluid is forced through a thin application cannula in a pulsatile manner. This cannula is surrounded by an external cannula that varies in diameter and arrangement of openings. The rate of flow for the infiltrative fluid and applied pressure are controlled/selected by the surgeon via a software guidance system. After the infiltration is performed, traditional liposuction is used to evacuate the subcutaneous fat. Like UAL,
WAL is a gentle, less traumatic form of suction lipoplasty and has advantages in large volume fat grafting; however, WAL does not provide inherent skin contraction following adipose aspiration. Although theoretical advantages have been touted, there is limited adoption of this technology in the United States. ${ }^{54-56}$ In one study, approximately 3\% of patients developed nodularity in the subcutaneous space within 6 weeks after surgery. Irregularities were successfully managed by a series of external ultrasound treatments and resolved by 3 months. ${ }^{56}$

\section{Aspirator devices}

There have been few refinements or technological advances to the equipment responsible for generating one atmosphere of negative pressure necessary to adequately perform liposuction. Most devices generate vacuum suction through high-powered dual-cylinder piston pumps or modular pumps (vapor pressure vacuum). ${ }^{57}$ Certain devices house a cooling fan to allow for pumps to run continuously as certain cases can last several hours. High-pressure tolerance tubing facilitates aspiration of the adipose tissue through the cannulas. Most devices contain a pressure gauge and generate up to $29+$ inches $\mathrm{Hg}$, which roughly translates to a negative pressure of $736 \mathrm{mmHg}$ or greater to safely aspirate the subcutaneous fat. Several companies offer varying lines of aspirator devices. Wells Johnson Co, (Tucson, AZ, USA) and Mentor Worldwide LLC (Santa Barbara, CA, USA) are two examples of manufacturers of vacuum suction generating aspiration equipment. ${ }^{58}$ Generally, these aspirator generators can be used with any of the other technology devices listed in the previous sections.

\section{Emerging medical technology RF-assisted liposuction}

As surgeons and scientists continued to explore combining surgical suction of subcutaneous adipose with technology to tighten skin/provide soft tissue contraction, increased interest has grown in utilizing RF as an adjunct to SAL. RF energy is high frequency oscillating electrical current (one million cycles per second) applied to the tissue to create a thermal effect. RF-assisted liposuction (RFAL) is responsible for dissolving fat cells, which leads to the creation of small channels in the fatty tissue. Furthermore, RFAL causes dermal physiologic responses including immediate contraction of the collagen fibers, subdermal remodeling, and neocollagen formation. ${ }^{59-61}$

RFAL is a computer controlled, bipolar RF device that simultaneously coagulates fat, aspirates the liquefied fat, 
and contracts the fibroseptal network (FSN). ${ }^{62}$ The first such technological advancement to employ RF for lipolysis is the BodyTite ${ }^{\mathrm{TM}}$ system (Invasix Ltd, Yokneam Ilit, Israel) (Figure 5). The internal electrode of the BodyTite ${ }^{\mathrm{TM}}$ is a hollow Mercedes-tip suction cannula/electrode and is silicone coated, except for the tip. The tip delivers RF, which flows to an external circular electrode that slides along the surface of the skin, in tandem with the internal electrode. This contact surface creates lower power density in the upper dermal layer and closes the RF current loop by receiving the energy through the skin. Furthermore, the external electrode has an imbedded thermal sensor that measures real-time skin temperature ten times per second, leading to uniform heating of the subreticular dermis, which aids in the denaturation and remodeling of collagen. ${ }^{11,59,63,64}$ This is an important concept and ensures patient safety by avoiding thermal injury which can result in deep burns and pathologic scarring. In addition, the pericanalicular temperature, high and low dermal impedance, and the external electrode contact are measured. There are safety RF cutoffs for each of these measured parameters, which greatly reduce the risk of a thermal injury. The two Bodytite $^{\mathrm{TM}}$ electrodes are connected to a handpiece that controls the depth of the internal electrode. Power settings, from 25 to $75 \mathrm{~W}$, result in RF being emitted from the tip which creates a thermal coagulative necrosis zone (approximately $90^{\circ} \mathrm{C}$ for $1.0 \mathrm{~cm}$ above the cannula), leading to adipose tissue coagulation and contraction of the FSN. ${ }^{62}$ The RFAL hand piece and the hollow internal cannula/probe are attached to suction, so there is simultaneous aspiration of the coagulated and liquefied fat. When the internal pericanalicular temperature reaches an average of $60^{\circ} \mathrm{C}$, the fat is liquefied, and the FSN has been stimulated and contracted. The Bodytite $^{\mathrm{TM}}$ safety features include computer-monitored external skin thermal sensors, high and low dermal impedance, and internal thermal sensors, as well as contact sensors. When the

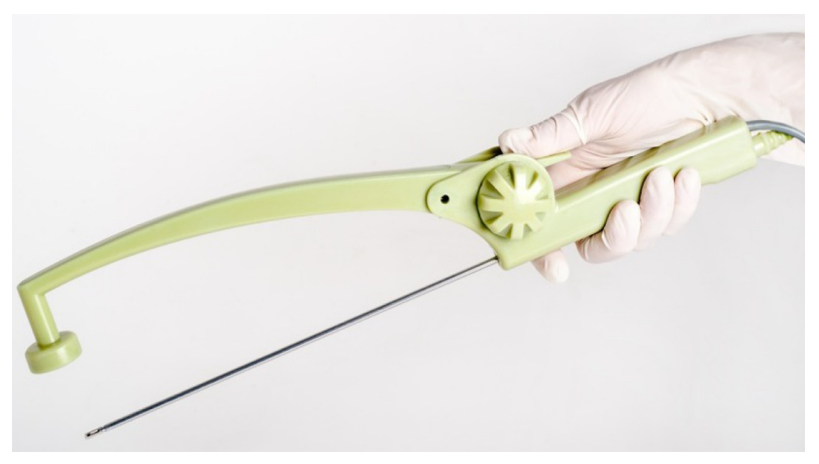

Figure 5 BodyTite ${ }^{\mathrm{TM}}$

Note: Invasix Ltd., Yokneam, Ilit, Israel. internal temperature or skin temperature is reached, the RF energy is cut off, alerting the physician when to proceed or stop. The RFAL generally never approaches more superficial than $2 \mathrm{~cm}$ from the skin surface. When the epidermis reaches $38^{\circ} \mathrm{C}-42^{\circ} \mathrm{C}$, the thermal heating and aspiration in the respective zone is complete. During the RFAL thermal procedure, approximately $30 \%$ of the desired aspiration occurs, and completion SAL or PAL contouring is performed.

One of the reported advantages of Bodytite ${ }^{\mathrm{TM}}$ and RFAL is the significant contraction of the skin and soft tissue, which has been reported to be $\geq 35 \%$ at 12 months compared with $<8 \%$ for standard SAL. ${ }^{65}$ Surgeons proficient in the Bodytite $^{\mathrm{TM}}$ technique can get very strong soft tissue contraction in zones with prominent FSN, without the need for aggressive subdermal liposuction or skin excision. While a theoretical disadvantage of the RFAL system is thermal injury to the surrounding dermal structures, there have been no reports of this within the peer-reviewed literature. Reported complications have been minimal, and include bruising, surface irregularities, and pain. ${ }^{63,64}$ The RFAL system shows promise and has a significant amount of international experience and data. FDA approval is pending.

\section{Future directions}

The "holy grail" for body-sculpting technology is noninvasive technologies that minimize tissue morbidity, decrease downtime, and increase skin contraction/tightening, which lessens the need for skin excision by way of surgical intervention. This has led to a new industry: noninvasive body contouring. The technology and products are beyond the scope of this liposuction technology update report; however, these nonsurgical adipose reducing techniques are on the horizon and available. The indications and outcomes are completely different than liposuction, and therefore, are not comparable.

Cryolipolysis is being routinely employed to decrease small target adipose deposits. Coolsculpt ${ }^{\mathrm{TM}}$ (Zeltiq, Pleasanton, CA, USA) (Figure 6) employs this technology. Cryolipolysis refers to using cold exposure to selectively induce subcutaneous fat necrosis by stimulating the inflammatory reaction/cascade within adipose tissue due to a response to the exposure to cold. ${ }^{61,66-68}$ A systematic review of 662 patients performed by the authors demonstrated a $22 \%$ reduction in subcutaneous fat deposits as measured by caliper thickness. Additionally, there was a minimal (4\%) reported complication rate, which included pain and contour irregularities. These complications resolved without intervention. 


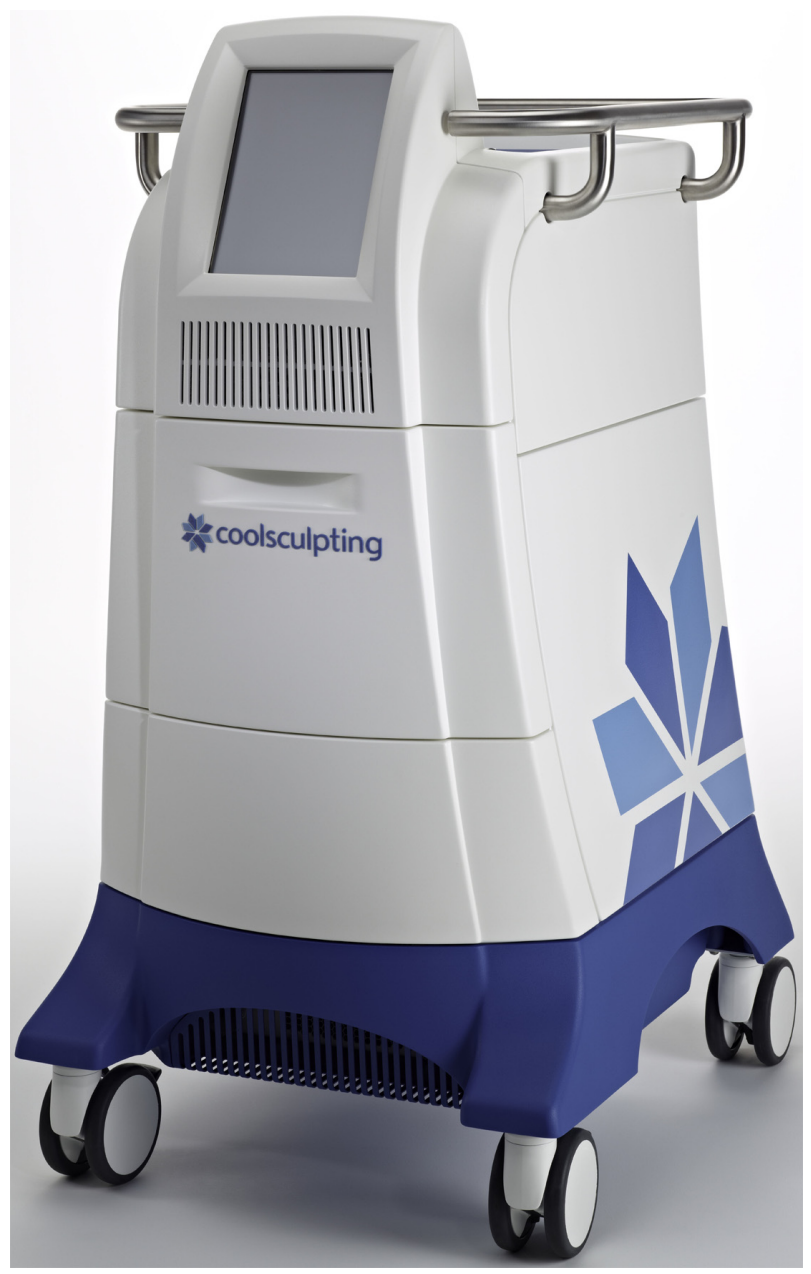

Figure 6 Coolsculpt ${ }^{\mathrm{TM}}$.

Note: Zeltiq, Pleasanton, CA, USA.

High-intensity focused ultrasound (HIFU) delivers focused, high-intensity ultrasonic energy to deep subcutaneous tissue. This effectively produces heat capable of ablating adipose tissue and thermally modifying collagen. The optimal HIFU frequency and intensity for body sculpting, which is capable of disrupting adipocytes and contracting collage fibers to tighten skin, is $2 \mathrm{MHz}$ and $>1,000 \mathrm{~W} / \mathrm{cm}^{2}$, respectively. ${ }^{69-72}$ One such product available is the Liposonix ${ }^{\mathrm{TM}}$ system from Solta Medical (Hayward, CA, USA) (Figures 7 and 8). Complications of using the device were minimal and included pain, surface irregularities, and subcutaneous nodules. All complications resolved without intervention. ${ }^{69}$

RF devices utilize optical energies delivered to the dermis/hypodermis. Optical infrared energy targets primarily the dermal water, whereas the RF energy targets the hypodermis by controlled thermal stress. The application of thermal energy to the dermis leads to dermal tightening and contraction. Furthermore, there is activation of physiologic responses inside the dermal fibroblasts to stimulate

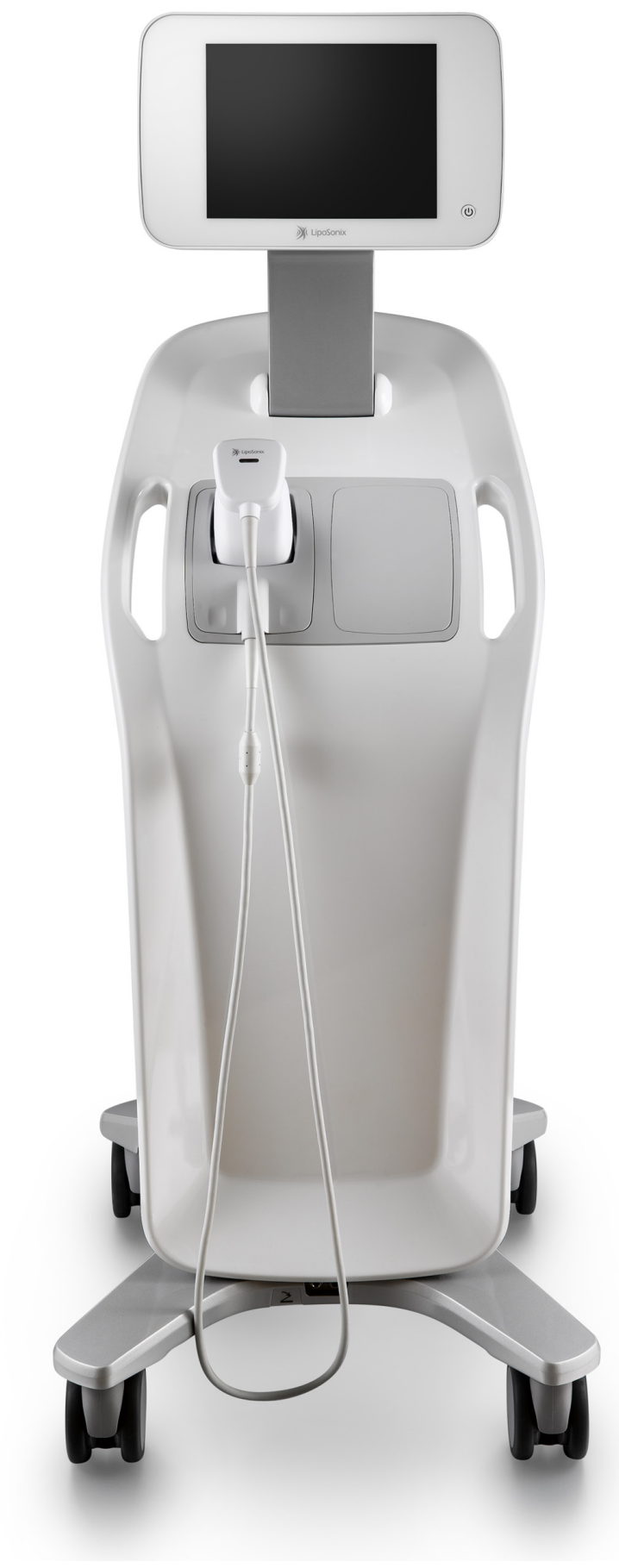

Figure 7 Liposonix ${ }^{\mathrm{TM}}$

Note: Solta Medical, Hayward, CA, USA.

collagen formation. The vacuum adjunct potentiates collagen formation by inducing mechanical stress factors on the dermal fibroblasts. The application of bipolar RF energy to the hypodermis increases fat cell metabolism and quickens triglyceride egress. ${ }^{73}$ Certain devices (BodyFX ${ }^{\mathrm{TM}}$; Invasix Ltd, Yokneam Ilit, Israel) use RF to preheat the dermis and first $15-20 \mathrm{~mm}$ of fat and use a precise thermistor built inside the suction cavity to monitor the skin temperature and suction 


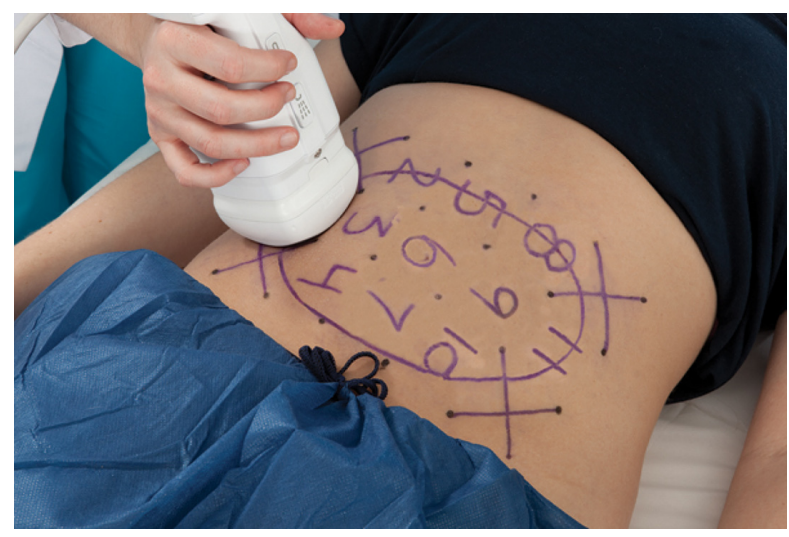

Figure 8 Liposonix ${ }^{\mathrm{TM}}$.

Note: Solta Medical, Hayward, CA, USA.

distribution. When the epidermal temperature reaches the desired level, a high-voltage, electroporation pulse is generated through the adipose tissue within the treatment field. Randomized, human tissue studies have shown a high voltage electroporation apoptotic effect on up to $30 \%$ of the adipocytes in the field of treatment, leading to a permanent RF induced fat reduction. ${ }^{74}$

The emerging technologies are unified in the goal to decrease subcutaneous fat deposits while providing dermal tightening. Additionally, these instruments aim to provide this result in a single use, minimally invasive application. While all of these emerging technologies fall short in achieving superiority over one another, they seemingly all have the same side-effect profile, which includes pain and surface irregularities. There is continued interest in modifying the technique by adding technologies with energy to optimize skin tightening and fat emulsification. Furthermore, recognizing the existence of adipose-derived stem cells and the capability of autologous fat grafting has led to the desire to study harvesting/ liposuction techniques to optimize graft survival. ${ }^{75}$

\section{Conclusion}

Liposuction technologies have significantly advanced over the last generation. Although liposuction continues to be one of the most widely performed cosmetic surgical procedures worldwide,${ }^{5}$ the procedure is a relatively "young" operation in surgical terms, with the first descriptions of the modern technique occurring in the $1980 \mathrm{s.}^{2}$ Although only in existence for roughly 30 years, the procedure has quickly become one of the most commonly performed cosmetic procedures worldwide. Numerous machines/systems exist. No one system has definitively proven to be superior to the other. Liposuction is a safe and reliable method of removing subcutaneous fat in order to create a more harmonious silhouette in a disagreeable biological condition caused by excess fat deposition in relatively common distribution patterns.

\section{Disclosure}

The authors have no commercial associations or financial disclosures that might pose or create a conflict of interest with information presented in this submitted manuscript (such associations include consultancies, stock ownership, or other equity interests, patent licensing arrangements, and payments for conducting or publicizing a study described in the manuscript).

\section{References}

1. Fodor PB. Suction mammaplasty: the use of suction lipectomy to reduce large breasts. Plast Reconstr Surg. 2000;105:2608-2610.

2. Illouz YG. Body contouring by lipolysis: a 5-year experience with over 3000 cases. Plast Reconstr Surg. 1983;72:591-597.

3. Reed LS. Lipoplasty of the calves and ankles. Clin Plast Surg Plast Reconstr Surg. 1989;16:365-368.

4. Simon BE, Hoffman S, Kahn S. Classification and surgical correction of gynecomastia. Plast Reconstr Surg. 1973;51:48-52.

5. The American Society for Aesthetic Plastic Surgery. Cosmetic Surgery National Data Bank Statistics 2012. New York: The American Society for Aesthetic Plastic Surgery. Available from: http://www. surgery.org/sites/default/files/ASAPS-2012-Stats.pdf. Accessed February 21, 2014.

6. Lewis CM. Early history of lipoplasty in the United States. Aesthet Plast Surg. 1990;14:123-126.

7. Apfelberg DB, Rosenthal S, Hunstad JP, Achauer B, Fodor PB. Progress report on multicenter study of laser-assisted liposuction. Aesthet Plast Surg. 1994;18:259-264.

8. Fodor PB, Vogt PA. Power-assisted lipoplasty (PAL): a clinical pilot study comparing PAL to traditional lipoplasty (TL). Aesthet Plast Surg. 1999;23:379-385.

9. Jewell ML, Fodor PB, de Souza Pinto EB, Al Shammari MA. Clinical application of VASER - assisted lipoplasty: a pilot clinical study. Aesthet Surg J. 2002;22:131-146.

10. Zocchi M. Ultrasonic liposculpturing. Aesthet Plast Surg. 1992;16: 287-298.

11. Theodorou SJ, Paresi RJ, Chia CT. Radiofrequency-assisted liposuction device for body contouring: 97 patients under local anesthesia. Aesthet Plast Surg. 2012;36:767-779.

12. Matarasso A. Discussion. Analysis of postoperative complications for superficial liposuction: a review of 2398 cases. Plast Reconstr Surg. 2011;127:872-873.

13. Shridharani SM, Wang HD, Singh NK. Liposuction. Eplasty. 2013;13:ic4.

14. Fodor PB. Reflections on lipoplasty: history and personal experience. Aesthet Surg J. 2009;29:226-231.

15. Schrudde's lipexhaerisis. Aesthet Plast Surg. 1991;15:365-366.

16. Schrudde J. [Lipectomy and lipexhaeresia in the area of the lower extremities (author's trans1)]. Langenbecks Arch Chir. 1977;345: 127-131. German.

17. Schrudde J. Lipexeresis as a means of eliminating local adiposity. Aesthet Plast Surg. 1980;4:215-226.

18. Schrudde J. Suction curettage for body contouring. Plast Reconstr Surg. 1982;69(5):903-904.

19. Schrudde J. Lipexheresis (liposuction) for body contouring. Clin Plast Surg. 1984;11:445-456.

20. Teimourian B, Fisher JB. Suction curettage to remove excess fat for body contouring. Plast Reconstr Surg. 1981;68:50-58. 
21. Teimourian B, Adham MN. Anterior periosteal dermal suspension with suction curettage for lateral thigh lipectomy. Aesthet Plast Surg. 1982;6:207-209.

22. Teimourian B. Face and neck suction-assisted lipectomy associated with rhytidectomy. Plast Reconstr Surg. 1983;72:627-633.

23. Teimourian B, Adham MN, Gulin S, Shapiro C. Suction lipectomy a review of 200 patients over a six-year period and a study of the technique in cadavers. Ann Plast Surg. 1983;11:93-98.

24. Teimourian B, Kroll SS. Subcutaneous endoscopy in suction lipectomy. Plast Reconstr Surg. 1984;74:708-711.

25. Teimourian B, Massac EJ, Wiegering CE. Reduction suction mammoplasty and suction lipectomy as an adjunct to breast surgery. Aesthet Plast Surg. 1985;9:97-100.

26. Georgiade NG. Essentials of plastic, maxillofacial, and reconstructive surgery. Baltimore: Williams \& Wilkins; 1987.

27. Kesselring UK, Meyer R. A suction curette for removal of excessive local deposits of subcutaneous fat. Plast Reconstr Surg. 1978;62: 305-306.

28. Kesselring UK. Suction curette for removal of subcutaneous fat. Plast Reconstr Surg. 1979;63(4):560.

29. Kesselring UK. Regional fat aspiration for body contouring. Plast Reconstr Surg. 1983;72:610-619.

30. Kesselring UK. Body contouring with suction lipectomy. Clin Plast Surg. 1984;11:393-408.

31. Illouz YG. Body Sculpting by Lipoplasty. New York: Churchill Livingstone; 1989.

32. Fournier PF, Otteni FM. Lipodissection in body sculpturing: the dry procedure. Plast Reconstr Surg. 1983;72:598-609.

33. Zocchi ML. Ultrasonic assisted lipoplasty. Technical refinements and clinical evaluations. Clin Plast Surg. 1996;23:575-598.

34. Rohrich RJ, Morales DE, Krueger JE, et al. Comparative lipoplasty analysis of in vivo-treated adipose tissue. Plast Reconstr Surg. 2000;105:2152-2158; discussion 2159.

35. Maxwell GP, Gingrass MK. Ultrasound-assisted lipoplasty: a clinical study of 250 consecutive patients. Plast Reconstr Surg. 1998;101: 189-202; discussion 203.

36. Rohrich RJ, Beran SJ, Kenkel JM, Adams WPJ, DiSpaltro F. Extending the role of liposuction in body contouring with ultrasound-assisted liposuction. Plast Reconstr Surg. 1998;101:1090-1102; discussion 1117.

37. Beckenstein MS, Grotting JC. Ultrasound-assisted lipectomy using the solid probe: a retrospective review of 100 consecutive cases. Plast Reconstr Surg. 2000;105:2161-2174; discussion 2175.

38. Fodor PB, Watson J. Personal experience with ultrasound-assisted lipoplasty: a pilot study comparing ultrasound-assisted lipoplasty with traditional lipoplasty. Plast Reconstr Surg. 1998;101:1103-1116; discussion 1117

39. Illouz YG. Complications of liposuction. Clin Plast Surg. 2006;33: 129-163, viii.

40. Zukowski ML, Ash K. Ultrasound-assisted lipoplasty learning curve. Aesthet Surg J. 1998;18:104-110.

41. Ahmad J, Eaves FF, Rohrich RJ, Kenkel JM. The American Society for Aesthetic Plastic Surgery (ASAPS) survey: current trends in liposuction. Aesthet Surg J. 2011;31:214-224.

42. Fodor P. Power-assisted lipoplasty. Aesthet Surg J. 2001;21:90-92.

43. Fodor PB. Power-assisted lipoplasty versus traditional suction-assisted lipoplasty: comparative evaluation and analysis of output. Aesthet Plast Surg. 2005;29(2):127.

44. Shridharani SM, Mohan R. A 51-year-old man with HIV and cervicodorsal lipodystrophy (buffalo hump). JAMA. 2013;309:1289-1290.

45. Apfelberg DB. Results of multicenter study of laser-assisted liposuction. Clin Plast Surg. 1996;23:713-719.

46. Anderson RR, Parrish JA. Selective photothermolysis: precise microsurgery by selective absorption of pulsed radiation. Science. 1983;220: $524-527$.
47. Badin AZ, Gondek LB, Garcia MJ, Valle LC, Flizikowski FB, de Noronha L. Analysis of laser lipolysis effects on human tissue samples obtained from liposuction. Aesthet Plast Surg. 2005;29:281-286.

48. Ichikawa K, Tanino R, Wakaki M. Histologic and photonic evaluation of a pulsed Nd:YAG laser for ablation of subcutaneous adipose tissue. Tokai J Exp Clin Med. 2006;31:136-140.

49. Khoury JG, Saluja R, Keel D, Detwiler S, Goldman MP. Histologic evaluation of interstitial lipolysis comparing a 1064, 1320 and 2100 $\mathrm{nm}$ laser in an ex vivo model. Lasers Surg Med. 2008;40:402-406.

50. Zelickson BD, Dressel TD. Discussion of laser-assisted liposuction. Lasers Surg Med. 2009;41:709-713.

51. DiBernardo BE. Treatment of cellulite using a 1440-nm pulsed laser with one-year follow-up. Aesthet Surg J. 2011;31:328-341.

52. DiBernardo BE, Reyes J. Evaluation of skin tightening after laserassisted liposuction. Aesthet Surg J. 2009;29:400-407.

53. Chia CT, Theodorou SJ. 1,000 consecutive cases of laser-assisted liposuction and suction-assisted lipectomy managed with local anesthesia. Aesthet Plast Surg. 2012;36:795-802.

54. Araco A, Gravante G, Araco F, Delogu D, Cervelli V. Comparison of power water-assisted and traditional liposuction: a prospective randomized trial of postoperative pain. Aesthet Plast Surg. 2007;31:259-265.

55. Man D, Meyer H. Water jet-assisted lipoplasty. Aesthet Surg J. 2007;27:342-346.

56. Sasaki GH. Water-assisted liposuction for body contouring and lipoharvesting: safety and efficacy in 41 consecutive patients. Aesthet Surg J. 2011;31:76-88.

57. Grams Medical. Grams Aspirator (Model S-300): An Efficient, Exceptionally Quiet, Portable, Deep Vacuum Aspirator for Surgery. Costa Mesa, CA: Grams Medical. Available from: http://www. gramsmedical.com/documents/Grams\%20Aspirator.pdf. Accessed February 21, 2014.

58. Mentor Worldwide LLC. MENTOR ${ }^{\circledR}$ body contouring products. Santa Barbara, CA: Mentor Worldwide LLC. Available from: http://www.mentorwwllc.com/global-us/Body.aspx. Accessed February 21, 2014.

59. Gold MH. Tissue tightening: a hot topic utilizing deep dermal heating. J Drugs Dermatol. 2007;6:1238-1242.

60. Hantash BM, Ubeid AA, Chang H, Kafi R, Renton B. Bipolar fractional radiofrequency treatment induces neoelastogenesis and neocollagenesis. Lasers Surg Med. 2009;41:1-9.

61. Zelickson BD, Kist D, Bernstein E, et al. Histological and ultrastructural evaluation of the effects of a radiofrequency-based nonablative dermal remodeling device: a pilot study. Arch Dermatol. 2004;140:204-209.

62. Paul M, Mulholland RS. A new approach for adipose tissue treatment and body contouring using radiofrequency-assisted liposuction. Aesthet Plast Surg. 2009;33:687-694.

63. Blugerman G, Schavelzon D, Paul MD. A safety and feasibility study of a novel radiofrequency-assisted liposuction technique. Plast Reconstr Surg. 2010;125:998-1006.

64. Ion L, Raveendran SS, Fu B. Body-contouring with radiofrequencyassisted liposuction. J Plast Surg Hand Surg. 2011;45:286-293.

65. Duncan DI. Nonexcisional tissue tightening: creating skin surface area reduction during abdominal liposuction by adding radiofrequency heating. Aesthet Surg J. 2013;33:1154-1166.

66. Avram MM, Harry RS. Cryolipolysis for subcutaneous fat layer reduction. Lasers Surg Med. 2009;41:703-708.

67. Manstein D, Laubach H, Watanabe K, Farinelli W, Zurakowski D, Anderson RR. Selective cryolysis: a novel method of non-invasive fat removal. Lasers Surg Med. 2008;40:595-604.

68. Mulholland RS, Paul MD, Chalfoun C. Noninvasive body contouring with radiofrequency, ultrasound, cryolipolysis, and low-level laser therapy. Clin Plast Surg. 2011;38:503-520, vii-viii.

69. Broyles JM, Shridharani SM. The safety and efficacy of cryolipolysis: a systematic review of available literature. American Society for Aesthetic Plastic Surgery. Annual Meeting; 2014; San Francisco. 
70. Fatemi A, Kane MA. High-intensity focused ultrasound effectively reduces waist circumference by ablating adipose tissue from the abdomen and flanks: a retrospective case series. Aesthet Plast Surg. 2010;34:577-582.

71. Jewell ML, Solish NJ, Desilets CS. Noninvasive body sculpting technologies with an emphasis on high-intensity focused ultrasound. Aesthet Plast Surg. 2011;35:901-912.

72. Jewell ML, Baxter RA, Cox SE, et al. Randomized sham-controlled trial to evaluate the safety and effectiveness of a high-intensity focused ultrasound device for noninvasive body sculpting. Plast Reconstr Surg. 2011;128:253-262.
73. Anolik R, Chapas AM, Brightman LA, Geronemus RG. Radiofrequency devices for body shaping: a review and study of 12 patients. Semin Cutan Med Surg. 2009;28:236-243.

74. Mulholland RS, Kreindel M. Non-surgical body contouring: introduction of a new non-invasive device for long-term localized fat reduction and cellulite improvement using controlled, suction coupled, radiofrequency heat and high voltage ultra-short electrical pulses. J Clin Exp Dermatol Res. 2012;3:1-9.

75. Magarakis M, Shridharani SM, Singh NK, Redett RJ. Adipose stem cells and regenerative medicine. New York: Springer, 2011.

\section{Publish your work in this journal}

Medical Devices: Evidence and Research is an international, peerreviewed, open access journal that focuses on the evidence, technology, research, and expert opinion supporting the use and application of medical devices in the diagnosis, treatment and management of clinical conditions and physiological processes. The identification of novel devices and optimal use of existing devices which will lead to improved clinical outcomes and more effective patient management and safety is a key feature. The manuscript management system is completely online and includes a quick and fair peer-review system. Visit http://www. dovepress.com/testimonials.php to read real quotes from authors.

Submit your manuscript here: http://www.dovepress.com/medical-devices-evidence-and-research-journal 